\title{
Why some electricity utilities actively promote energy efficiency while others do not—a Swiss case study
}

\author{
Yann Benedict Blumer • Martin Mühlebach • \\ Corinne Moser
}

Received: 23 April 2013 / Accepted: 26 December 2013 /Published online: 1 February 2014

(C) Springer Science+Business Media Dordrecht 2014

\begin{abstract}
Electricity utilities are key players for promoting energy efficiency (EE) because of their close link to consumers. Utility-centered EE policy frameworks, such as white certificate schemes coupled to saving obligations, have been shown to be both effective and efficient in several US states and various European countries. In Switzerland, where such a policy framework is absent on a national level, large differences occur among utility providers in their activities to promote EE. This study sheds light on this issue, using data from a survey of Swiss utilities $(N=114)$. A two-step cluster analysis was used to identify three groups of utilities. It is based on these utilities' evaluation of 20 incentives and constraints for promoting EE. An analysis of variance found significant differences between the clusters regarding size (number of employees), share of
\end{abstract}

Electronic supplementary material The online version of this article (doi:10.1007/s12053-013-9249-z) contains supplementary material, which is available to authorized users.

Y. B. Blumer $(\bowtie) \cdot$ M. Mühlebach $\cdot$ C. Moser

Natural and Social Science Interface, Institute for

Environmental Decisions, ETH Zurich,

Universitätsstrasse 22, 8092 Zurich, Switzerland

e-mail: yann.blumer@env.ethz.ch

\section{Y. B. Blumer}

Human-Environment Systems Group, Institute for Environmental Decisions, ETH Zurich,

Universitätsstrasse 22, 8092 Zurich, Switzerland

C. Moser

Institute of Sustainable Development, ZHAW School of

Engineering,

Technoparkstrasse 2, 8401 Winterthur, Switzerland production, number of large clients, and - most importantly-level of activity in implementing EE programs. The most active cluster comprises mainly larger utility companies, which primarily see the incentives of promoting EE. The passive cluster consists of small companies, focusing primarily on constraints. There is also an ambivalent cluster. It includes middle-sized companies, which see both clear incentives and many constraints - mainly a lack of human and capital resources - for engaging in EE. Based on our analysis, we conclude that due to the large heterogeneity of Swiss utilities, there is a need for contextualized policies targeting different types of utilities in order to effectively promote EE.

Keywords Energy efficiency · Utilities · Cluster analysis $\cdot$ Switzerland

\section{Introduction}

After the accident at the Japanese Fukushima Daiichi nuclear power plant in March 2011, Switzerland decided to phase out nuclear power production. In order to accomplish this objective, the Swiss government developed a new energy strategy. A key pillar of this strategy is the more efficient use of electricity in order to reduce the domestic per capita demand by about $20 \%$ until 2050 compared to 1990 levels (Swiss Federal Council 2013). In addition to helping to reduce the gap between supply and demand, the promotion of energy efficiency (EE) is important to curb carbon emissions (Ürge- 
Vorsatz and Metz 2009), to minimize other negative environmental impacts caused by the production of electricity, such as land use (Fthenakis and Kim 2009), and to ensure the security of supply in the face of the world's rising demands for energy (Yergin 2006).

With respect to the practical implementation of EE measures, energy companies with a retail function have been identified as key actors because of their extensive knowledge of and strong link to consumers (Pavan 2012). Hence, utilities ${ }^{1}$ have become the focus of policymakers. This, for example, is the case in the UK, where " $(. .$.$) government policy is strongly, and increas-$ ingly, geared towards using energy suppliers as agents for demand reduction, as they have been the agents for getting efficiency measures into homes" (Pyrko and Darby 2011, p. 401). Also in the new Swiss energy strategy, utilities are expected to play a key role for reaching national energy efficiency targets (Swiss Federal Council 2013). However, there is a fundamental conflict between utilities' role as promoters of EE and their traditional business models, as their revenue is proportionally linked to their energy sales. In order to overcome this so-called throughput incentive, many governments have established policy frameworks that alter utilities' commercial logic by decoupling their revenues and sales (Sullivan et al. 2011; Zarnikau 2012). One prominent example of this is the US state of California (see, for example, Kaufman and Palmer 2012).

Most of these policy frameworks comprise a mechanism for setting utility-specific saving obligations, i.e., quantitative and clearly defined EE targets set by a regulatory body. Such saving obligations may "be coupled with various trading options" (Bertoldi and Resessy 2009, p. 4). Out of these options, white certificates - certified tradable energy savings-have received particular of attention in scientific literature. Several empirical studies in various EU countries (Bertoldi et al. 2010; Giraudet et al. 2012; Mundaca 2008; Suerkemper et al. 2012) and in Australia (Crossley 2008) have assessed the performance of such policy frameworks that make use of white certificates. There is a wide agreement that these can contribute to a costefficient reduction of energy consumption. However, to

\footnotetext{
${ }^{1}$ In this article, we use the term utilities to refer to electricity companies with a retail function, regardless of whether they are as well energy producers or provide other utility services, such as gas or water.
}

ensure a level playing field for all market participants, such a decoupling framework requires both a consistent legal basis on a national or at least regional level, as well as an administrative body that has adequate resources to monitor the system and its participants.

Since these conditions do not apply to Switzerland, the implementation of such a decoupling framework on a national level is not yet in place. But even despite this lack of such a framework, there are some Swiss utilities that currently provide a broad range of services to encourage their customers in becoming more efficient, while others are very passive (Swiss Federal Council 2013). One reason for this disparity could be the highly fragmented Swiss electricity market, consisting of roughly 800 heterogeneous utilities. These range from small local companies with annual retail electricity sales of less than $1 \mathrm{GWh}$ to large, regionally active companies selling more than $8,000 \mathrm{GWh}$ every year. Swiss utilities also differ in terms of their degree of vertical integration. While some own significant generation capacities, most are merely resellers of electricity. Furthermore, while the transmission grid is owned by the Swiss transmission system operator, most of the distribution grid is owned by local utilities. Hence, no clear distinction between suppliers and distributors can be made in Switzerland. A reason for this is the Swiss electricity retail market, whose liberalization process is still in an intermediary stage. Only since 1 January 2009 have customers with an annual consumption of more than $100,000 \mathrm{kWh}$ been able to freely choose their electricity supplier. This option will at the earliest be available to smaller customers, such as residential ones, from 2015 onwards.

Up to this date, there have only been a few studies on the possible influences on the utilities' decisions to promote EE, and it is unclear how these findings can be transferred to the Swiss context. These studies have either had a very narrow focus and did not include potentially relevant characteristics of the utilities (such as their size), such that by Eurelectric (2011), or they focused on utilities facing a legal background not comparable to that in Switzerland (e.g. Hopper and colleagues (2009) or Carley (2012), that both focusing on North American utilities). Hence, for a better understanding of the Swiss case, a more specific study is needed. This is the goal of the study at hand. First, we provide an overview of the existing literature to identify external factors and company characteristics that might 
act as incentives or constraints for a utility promoting EE. Based on a large survey of the utilities in Switzerland, we then seek reasons why some electricity utilities promote EE while others do not, even in the absence of a respective national policy framework.

\section{Conceptual background}

In their analysis of differences among the activities of utilities for promoting EE, Waide and Buchner (2008, p. 299) refer to two prerequisites for turning "the poachers into the gamekeepers": They need to be both motivated and (financially and organizationally) capable of implementing an EE program. It is clear that these two factors are linked - a utility that is motivated to promote $\mathrm{EE}$ is more likely to free the required resources, while an apparent lack of motivation might outright stifle any such initiative. Nevertheless, in this study, we attempt to disentangle these factors by separately addressing the perceived incentives and constraints of the utilities (to address their motivations to engage in EE) and their specific characteristics (to address their capabilities to implement the necessary measures).

Incentives and constraints of utilities for promoting energy efficiency

The incentives and constraints for the promotion of EE by utilities have been the focus of a wide range of scientific literature, which we present below. To enable a clear overview, we have structured them according to five categories that served as the basis for the design of our survey (see "Utilities' activity to promote energy efficiency" section).

Policy framework is a key motivation as it can alter the commercial logic for utilities to engage in EE. The impact on the utilities' EE activities may be indirect, such as a government carbon emission goal, or it can be quite direct, as in California, where the Public Utility Commission sets concrete long-term EE goals for investor-owned utilities (Hopper et al. 2009). In Switzerland, the legal framework is largely the same for all utilities, but it has been undergoing drastic changes due to the liberalization of the retail market in 2009. Its prospects are uncertain, as they are linked to the negotiations regarding a better integration of the Swiss electricity market into that of the European Union, a process that began in 2010 and is ongoing. According to a survey of European electricity distribution companies, an unstable legal framework is a key barrier for the promotion of EE (Eurelectric 2011).

While demand growth is usually positive for utilities' revenues, it can also present a number of challenges (Hopper et al. 2009; Zarnikau 2012). Of these, ensuring the availability of electricity, either by increasing production or by purchasing it from external suppliers, is small compared to the efforts needed to prevent grid congestion during high demand periods. Therefore, utilities exposed to projected demand growth by their customers are more likely to adopt EE measures to reduce necessary investments in the distribution system. Due to Switzerland's tight rate-of-return regulation for investments in the electricity grid, demand growth could be a relevant incentive for Swiss utilities to promote EE.

If a utility regards EE programs as an opportunity to better position itself in the market (e.g., by improving its access to customers or by developing new lines of business such as contracting models), it will be more motivated to actively promote EE (Pyrko and Darby 2011). In these cases, the promotion of $E E$ can be regarded as a strategic investment to gain a competitive advantage (Cooremans 2011) ${ }^{2}$. However, if a utility decides to maintain its traditional business model, either because it wants to avoid the risk of investment or because it does not have the resources to develop a new one, the resulting conflict with the goals of the EE programs will strongly inhibit their implementation.

Another major factor is a utility's expectations regarding the financial performance of EE programs. On the one hand, this is linked to the high investments and long-term obligations required for certain EE programs (Eurelectric 2011) such as contracting models. On the other hand, it is also influenced by the difficulty in tracking the performance of EE programs in both energetic and financial terms (Vine et al. 2012).

Last, but certainly not least, a major incentive for a utility to engage in an EE program is marketing. Energy issues are currently high on the agenda of both policymakers and the media, and thus of public interest. Being perceived as "green" may thus significantly

\footnotetext{
${ }^{2}$ Although Cooremans does not explicitly address energy utilities but rather focuses on companies in general, her argument is still valid, as EE programs might be a strategic means for utilities to set them apart from competitors.
} 
improve a company's public image (Cooremans 2011) and attract new or different customers.

Company characteristics influencing its promotion of energy efficiency

Whether a utility is capable of implementing an EE program depends on its characteristics. One key characteristic might be the size of the company, since this reflects its financial and human resources as well as the marketing and engineering know-how to implement EE activities efficiently (Waide and Buchner 2008). This is only possible if the company has resources in excess of those needed to execute its core business and is thus able to adapt to changing business environments, which is usually referred to as organizational slack (see, for example, Tan and Peng 2003). Because the average Swiss utility is small, size might be of particular relevance to them, as a study on the challenges of partial electricity market liberalization for Swiss utilities suggests (Sonderegger 2005).

Its legal form may also be a relevant factor in determining how well a company is capable of implementing EE measures, as it may strongly influence internal decision-making processes. This is linked to the ownership of the utility. A North American study showed, for example, that investor-owned utilities have higher energy saving targets than others (Hopper et al. 2009), and another study found that municipal utilities are less likely to participate in EE programs than private ones or cooperatives (Carley 2012). The reason for this difference might be more stringent regulations or that the utilities set up as companies instead of administrations have a stronger incentive to strategically position themselves in a liberalized market. However, there are different views on the effect of utility ownership and its activity in promoting EE. Vojdani (2008), for instance, claimed that for investor-owned utilities in the United Stated, energy conservation usually has a rather low priority. The argument can even be made that publicly owned utilities promote EE more actively because governments use them as direct means to reach political goals, such as the recent evaluation of an EE program that was part of a political energy reduction plan (Cabrera et al. 2012). Although these findings might not be directly applicable to the Swiss context, legal form and ownership might still be relevant factors for explaining differences in the promotion of EE.
With regard to the share of own production of the electricity sold to customers, Swiss utilities differ greatly. While most are re-sellers of electricity, some have considerable power production capacities. Especially those companies that cover all of the demand with their own production or those that are even net exporters have the adequate know-how in selling their excess electricity. At the same time, they have an incentive to promote EE activities of their customers as this increases the amount of electricity that they can sell to other utilities. As most Swiss utilities with own production capacities have hydropower plants and as most of their customers are still in fixed tariff models, these companies may expect to realize higher returns if they sell their excess electricity on the retail market, at least during peak hours.

\section{Data base and study design}

Sample and procedure

We base our analysis on data collected among 296 Swiss electricity utilities in an online survey conducted between May 25 and June 12, 2012. It was translated and distributed in all three official Swiss languages (German, French and Italian, see Table S1, Electronic supplementary material (ESM), for more information). The invitation, as well as two reminders (after 1 and 2 weeks), were sent out by e-mail to all those members of the Association of Swiss Electricity Companies (VSE) (German: Verband Schweizerischer Elektrizitätsunternehmen), whose main business is the supply of electricity to consumers. The rest of the VSE members were not included, as these are primarily producers of electricity without a direct link to consumers. Although not all Swiss utilities are members of VSE, their members' sales account for the vast majority of the Swiss electricity retail market, since most of the nonmember utilities are very small in size.

Of 296 utilities, 114 (38.5\%) responded. Of these, 13 were excluded from further analysis due to missing data (dropouts). This response rate is comparable to that of other utility surveys conducted in Switzerland (e.g. Cometta et al. 2010; Sonderegger and Schedler 2010; Laager et al. 2009). Size distributions of the responding companies are similar to the study conducted by Sonderegger and Schedler (2010, see Fig. S1 in the ESM for details). The overall amount of electricity sold 
to end-consumers in 2011 by the participating companies was about $34 \mathrm{TWh}^{3}$. Compared to the overall Swiss power consumption of 58.6 TWh in the same year (BFE 2012), our sample covers almost $60 \%$ of the volume of the Swiss electricity market.

The survey consisted of three parts. In the first part, the utilities were asked to indicate their activities for promoting energy efficiency of their customers (see "Utilities' activity to promote energy efficiency" section). The second required them to provide their perspective on incentives and constraints to engage in such activities (see "Perceived incentives and constraints" section), and the third part inquired about the specific characteristics of these companies (see "Utility characteristics" section).

\section{Utilities' activity to promote energy efficiency}

There is no ideal measure for a utility's activity in improving their customers' EE. But in survey studies in particular, it is important to have a standardized and hence comparable basis. Therefore, we used the companies' different activities to support their customers in becoming more energy efficient as a dependent variable. Hence, in the survey, we provided a list of nine different energy efficiency services and the respondents were asked to check which of them their company offered. We made sure to include all EE services that had been established by at least some Swiss utilities by having two experts validate the list.

Using that data, we computed the EE performance of a utility $P_{\mathrm{EE}}$ (see Eq. 1) as a weighted sum of all services offered $p_{E E, i}$. The weighting $w_{i}$ reflects the assumed relative effectiveness of these services with regard to energy efficiency improvements and achieves a normalization. Thus, $P_{\mathrm{EE}}$ may range between 0 and 100 . This accounts for the fact that, for example, offering tariff incentives for customers who reduce their energy consumption is more effective than only providing information material. The weights of the different measures were derived from the evaluations of an expert panel $(N=9)$. The panel included two representatives of the Swiss Federal Office of Energy, one energy consultant, one researcher, and five CEOs of electricity utilities. As all of these five CEOs manage companies that had participated in the survey, we were able to ensure that

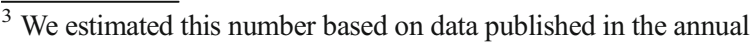
reports and on the websites of these utilities.
}

a broad spectrum of perspectives was represented (i.e., utilities of different sizes, degrees of energy efficiency activity and regions).

$P_{\mathrm{EE}}=\sum_{i=1}^{9} w_{i} \cdot p_{\mathrm{EE}, i}$

We used a scale ranging from 1 (no real effect, only "window dressing") to 7 (significant effect, may help to reduce a consumer's electricity consumption by up to $15 \%$ ). As a reference for the upper end of the scale, we used a report by Nabe et al. (2009) for the German Bundesnetzagentur (the regulatory body for electricity, gas, telecommunications, post and railway markets), in which tariff agreements were estimated as an EE service with a saving potential of 13 to $20 \%$ of a consumer's demand. The list of services, the average effectivity rating $(M)$ by the experts, the standard deviation $(S D)$ and the resulting weights for this study are presented in Table 1. For a more detailed overview of the experts' answers, please see Fig. S4 of the additional material.

Table 1 Services adopted by Swiss utilities to promote energy efficiency

$M \quad$ SD Weight

(\%)

Tariff agreements for large clients ${ }^{\mathrm{a}}$
Tariff incentives ${ }^{\mathrm{b}}$
Development of lighting concepts for
customers
Promotion of efficient appliances
(e.g., by providing financial bonuses)
Energy audits
Raising awareness by distributing energy
meters
Organization of public events
(e.g., booth at exhibitions)
Providing information material
(in print and/or online)
Efficiency consulting by phone
(e.g., hotline)

$\begin{array}{lll}5.9 & 1.0 & 15.5\end{array}$

$\begin{array}{lll}5.8 & 1.6 & 15.2\end{array}$

$\begin{array}{lll}5.4 & 1.2 & 14.2\end{array}$

$4.4 \quad 1.6 \quad 11.6$

$\begin{array}{lll}4.3 & 1.3 & 11.3\end{array}$

$\begin{array}{lll}3.8 & 1.2 & 9.9\end{array}$

$\begin{array}{lll}3.0 & 1.5 & 7.8\end{array}$

$\begin{array}{lll}2.9 & 2.0 & 7.7\end{array}$

$\begin{array}{lll}2.6 & 1.4 & 6.8\end{array}$

Sum

100 
Perceived incentives and constraints

In the survey, the utilities had been asked to provide their perspective on factors that both encouraged or discouraged them from promoting energy efficiency (i.e., their perceived incentives and constraints). Table 2 provides an overview of all variables used in the study. It consists of 20 binary (yes/no) variables, of which 10 refer to incentives and 10 to constraints. The selection of incentives and constraints was based on the categories presented in "Incentives and constraints of utilities for promoting energy efficiency" section and on a Swiss study conducted by Laager et al. (2009), which suggests that particularly for many smaller Swiss utilities the lack of resources might be quite a relevant barrier. Therefore, we have added a sixth category with four constraint

Table 2 List of incentives and constraints included in the survey structured according to six broad categories

\begin{tabular}{|c|c|c|}
\hline Category & Item & Mechanism \\
\hline \multirow[t]{4}{*}{ Resources } & Lack of personnel & Constraint \\
\hline & Lack of time & Constraint \\
\hline & Lack of know-how & Constraint \\
\hline & Lack of capital & Constraint \\
\hline \multirow{2}{*}{$\begin{array}{l}\text { Policy } \\
\quad \text { framework }\end{array}$} & Lack of adequate legal framework & Constraint \\
\hline & Meeting political goals & Incentive \\
\hline \multirow[t]{3}{*}{ Demand growth } & $\begin{array}{l}\text { Reducing dependence from } \\
\text { electricity suppliers }\end{array}$ & Incentive \\
\hline & $\begin{array}{l}\text { Reducing capital expenditure } \\
\text { for grid upgrades }\end{array}$ & Incentive \\
\hline & $\begin{array}{l}\text { Reducing capital expenditure } \\
\text { for new production capacities }\end{array}$ & Incentive \\
\hline \multirow[t]{6}{*}{ Positioning } & $\begin{array}{l}\text { Not a goal of the corporate } \\
\text { strategy }\end{array}$ & Constraint \\
\hline & $\begin{array}{l}\text { Leader is pushing the topic } \\
\text { of EE }\end{array}$ & Incentive \\
\hline & Meeting corporate goals & Incentive \\
\hline & Low priority in corporate strategy & Constraint \\
\hline & $\begin{array}{l}\text { Prospects of starting a new } \\
\text { business line }\end{array}$ & Incentive \\
\hline & Improving access to customers & Incentive \\
\hline \multirow[t]{2}{*}{$\begin{array}{l}\text { Financial } \\
\text { performance }\end{array}$} & $\begin{array}{l}\text { EE programs yield too little } \\
\text { financial return }\end{array}$ & Constraint \\
\hline & $\begin{array}{l}\text { Difficult to track the performance } \\
\text { of EE programs }\end{array}$ & Constraint \\
\hline \multirow[t]{3}{*}{ Marketing } & Acquiring new customers & Incentive \\
\hline & Improving the companies' image & Incentive \\
\hline & $\begin{array}{l}\text { A utility is not a credible promoter } \\
\text { of EE }\end{array}$ & Constraint \\
\hline
\end{tabular}

items that refer to a lack of resources for implementing EE measures.

\section{Utility characteristics}

In order to characterize the utilities with regard to their capabilities to implement EE programs we have been using the following four variables:

- We chose to measure utility size by the number of employees, as this is a better indicator of organizational capacity than the amount of electricity sold to customers. We expected that the EE performance of utilities increases with the number of their employees, due to their greater organizational slack.

- The legal form has been included as a binary variable. It separates utilities that are part of a local administration from those who have other legal forms. From the latter group, most are incorporated companies that are owned by communities. But it also includes some privately owned incorporated companies as well as some very few cooperatives. Being aware that there are diverging opinions on this issue in literature, we expected utilities set up as companies instead of administrations to have a higher EE performance than the others, as they have a stronger interest in positioning themselves strategically in the developing Swiss electricity market.

- We also expected the EE performance of a utility to increase with its share of produced electricity. For one, this is an indicator of organizational know-how of the electricity market. Furthermore, in times of rising market prices, being able to sell any excess electricity is attractive. This is especially true for peak hours, as Swiss utilities' production portfolio primarily consists of hydropower plants and most customers pay fixed tariffs.

- The number of large clients (consuming more than $100 \mathrm{MWh} / \mathrm{a}$ of electricity) has been included as a measure of a utility's market exposure. We expected that a high market exposure increases the pressure on utilities to offer EE services to these large customers and to at least consider EE as a means of positioning themselves in the electricity market, which is developing in Switzerland. We furthermore assume that utilities that have made such strategic reflections are likely to have identified at least some low-threshold measures, which they then implement. 


\section{Statistical analysis}

We first show some main characteristics of our sample of utilities, as well as the results of a linear regression analysis, in order to get some first insights into how these might be linked to EE performance. We then present the results of a cluster analysis that yielded three groups of utilities with similar perspectives on incentives and constraints for promoting EE. We used an analysis of variance (ANOVA) to determine whether any significant differences exist among these clusters. Finally, we applied an analysis of co-variance (ANCOVA) in order to allow for a closer look on the interactions of several variables in explaining the variances in EE performance among the utilities.

Overview of the sample of Swiss electricity utilities

The utilities in our sample are quite heterogeneous, and differ in size, number of large clients, and share of production. This is visible in Table 3, which shows means $(M)$, standard deviation (SD), minimum (min) and maximum $(\max )$ values for the EE performance, number of large clients, share of production (in percent) and number of employees of our sample of Swiss utilities $(N=101)$. Also with respect to $P_{\mathrm{EE}}$ there are large differences between the companies: while some provide a wide range of services, others do not offer any at all. With regard to legal form, there is an almost even split between those that are part of an administration $(n=53)$ and others $(n=48)$ that are not.

\section{Linear regression}

Using a linear regression analysis, we have analyzed the influence of four utility characteristics on their EE performance. We found a significant effect for both the number of employees and the legal form, meaning that a large, incorporated utility is more likely to have a high $P_{\mathrm{EE}}$ score than a small one that is part of an

Table 3 Overview of sample of Swiss utilities

\begin{tabular}{lllll}
\hline & $M$ & SD & Min & Max \\
\hline EE performance $\left[P_{\mathrm{EE}}\right]$ & 36.2 & 20.1 & 0 & 88.4 \\
Number of large clients & 69.4 & 101.1 & 0 & 500 \\
Share of production [\%] & 16.8 & 31.3 & 0 & 140 \\
Number of employees & 54.8 & 109.7 & 1 & 746 \\
\hline
\end{tabular}

administration. However, no effect could be found for the number of large clients and utilities' share of production (see Table 4). In our sample, there are two utilities that have a considerably higher number of employees than all the others and thus dominate the regression with regards to company size. When removing these two outliers, the effect of this variable became even more pronounced and none of the others were significant any longer (for more details we refer to the Table S2 of the ESM). From the regression analysis, it becomes clear that the four company characteristics chosen for our analysis only explain a minor share of variance in EE performance.

\section{Cluster analysis}

We applied a cluster analysis to identify groups of utilities that have similar incentives and constraints in promoting EE. A two-step procedure was chosen because the clustering was based on the 20 binary incentives and constraints variables. This method is based on a data clustering algorithm developed by Tian et al. (1997), which is capable of handling categorical variables (SPSS Inc. 2001). We used Schwarz's Bayesian criterion for the automatic determination of the number of clusters, which yielded three clusters.

The three groups of utilities derived from the cluster analysis were labeled active, passive, and ambivalent. This is based on the companies' profiles of their perspectives on the 20 incentives and constraints for engaging in energy efficiency (see Figs. 1 and 2).

The active cluster contains 35 utilities. They primarily focus on incentives to promote EE (on average, 4.3 out of the 10 potential incentives applied to them, standard deviation=1.5), whereas the constraints are clearly less relevant to them $(M=2.3, \mathrm{SD}=1.0)$. Its members have the highest approval rate for most of the incentives

Table 4 Results of the regression analysis with respect to utilities' EE performance

\begin{tabular}{lllll}
\hline & $B$ & Std. error $b$ & $\beta$ & $t$ \\
\hline Number of employees & 0.05 & 0.02 & $0.28^{*}$ & 2.561 \\
Number of large clients & 0.00 & 0.02 & 0.01 & 0.129 \\
Share of production [\%] & 0.00 & 0.07 & 0.00 & 0.016 \\
Legal form & 0.05 & 3.92 & $0.23^{*}$ & 2.311 \\
\hline$R^{2}=0.14$ & & & & \\
$* p<0.05$ & & & &
\end{tabular}




\section{Incentives to promoting energy efficiency}

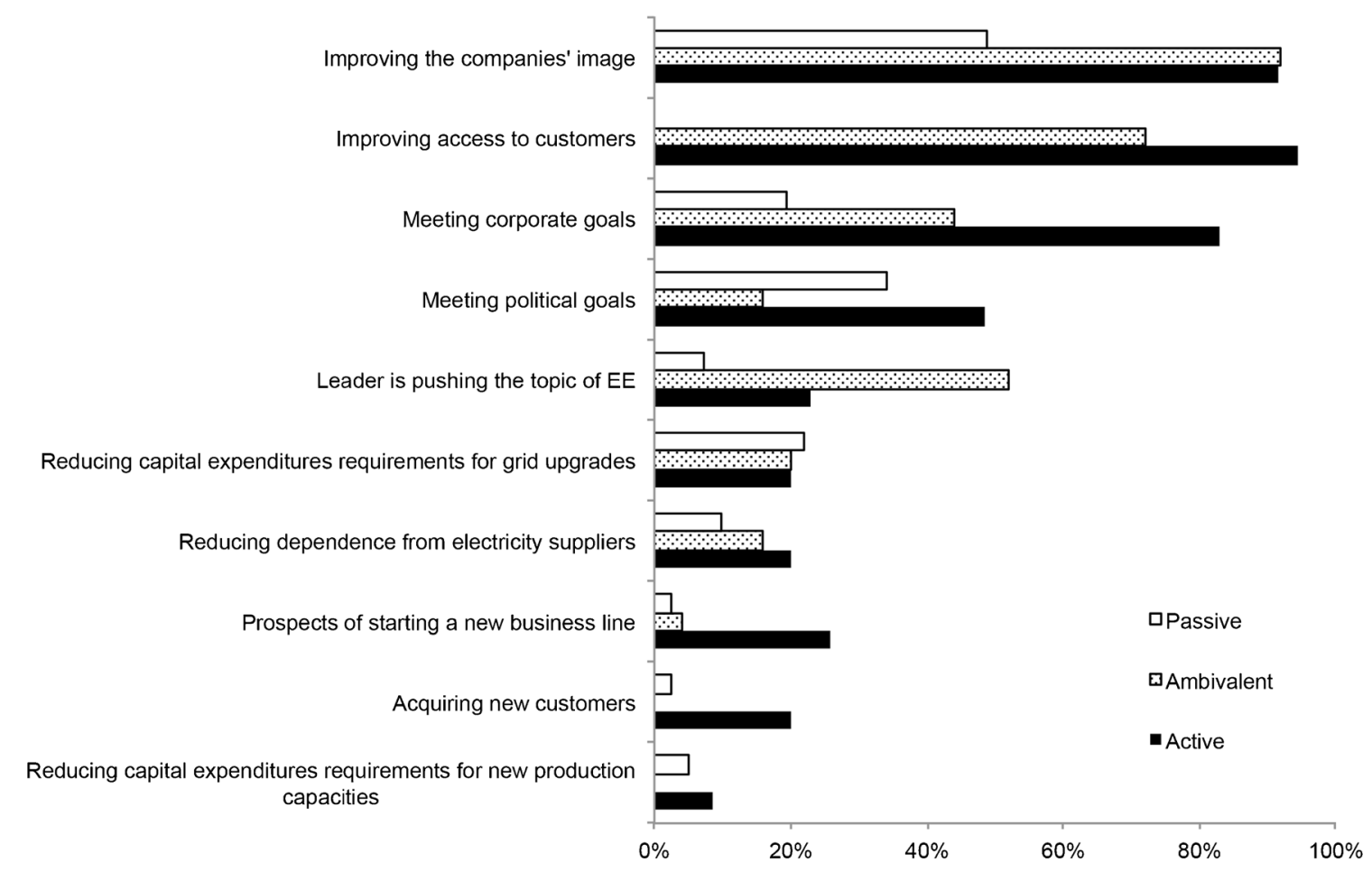

Fig. 1 Shares of utilities for which the 10 incentives were relevant, presented by cluster

\section{Constraints to promoting energy efficiency}

Lack of personnel

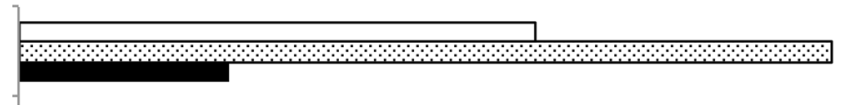

Lack of time

Difficult to track the performance of EE programs

Lack of adequate policy framework

EE programs yield too little financial returns

Lack of capital
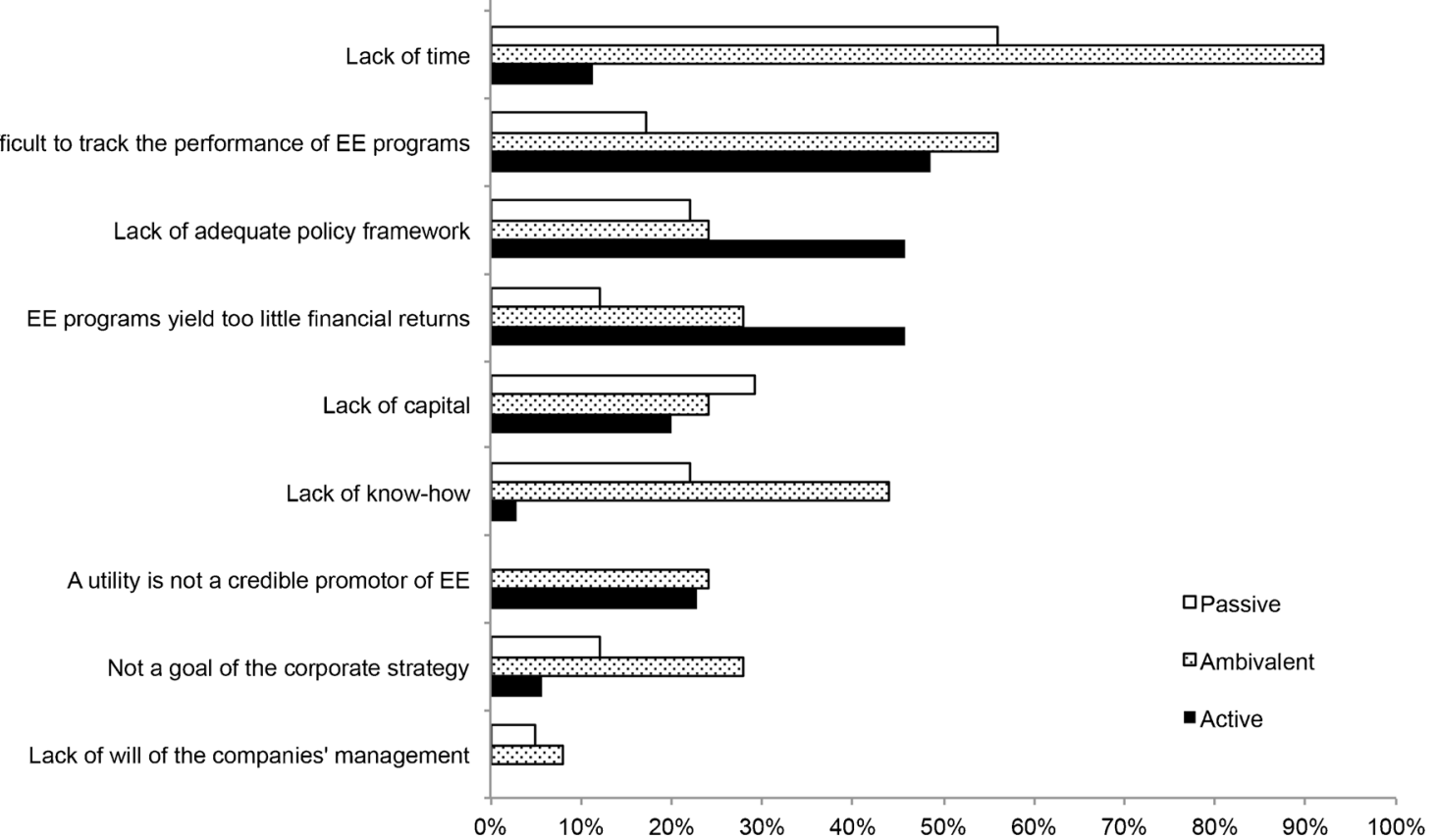

Fig. 2 Shares of utilities for which the 10 constraints were relevant, presented by cluster 
and the lowest for most constraints. The only variables that deviated from this pattern were the motivation leader is pushing the topic as well as the two constraints lack of adequate policy framework and EE programs yield too little returns (see Figs. 1 and 2). The cluster of active utilities also has the highest average EE performance (see Fig. 3). Compared to the others, the active cluster has a relatively high share of incorporated companies (69\%).

The passive cluster is the largest of the three, containing 41 utilities. It is immediately apparent that these companies perceive only few incentives to promote $\mathrm{EE}$ $(M=1.5, \mathrm{SD}=0.9)$ and consequently hold the lowest average approval rate for most of these items (see Fig. 1). The average sum of constraints is as high as that for the active cluster $(M=2.3, \mathrm{SD}=1.5)$, but displays a different pattern (see Fig. 2). For example, these utilities rate lack of personnel and lack of time much higher (although not as high as the ambivalent cluster). The passive utilities had the lowest average EE performance of all clusters (see Fig. 3) and compared to the others, also had a relatively low share of incorporated companies $(29 \%)$.

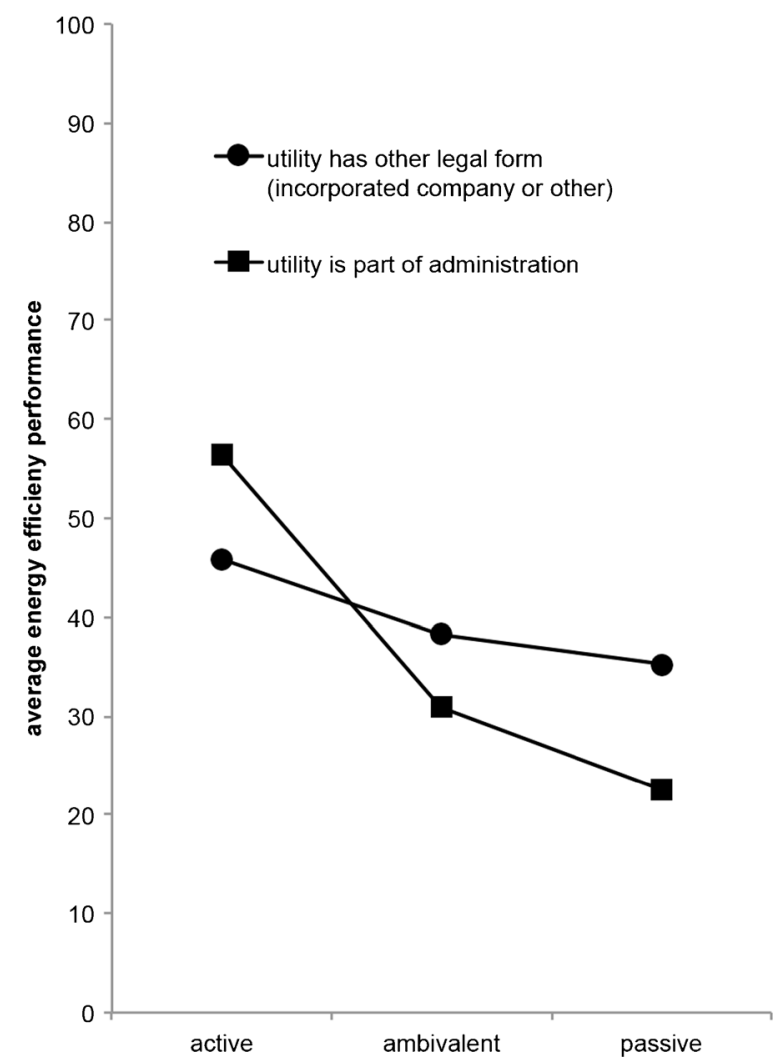

Fig. 3 Interaction effect between cluster membership and legal form
The cluster of ambivalent utilities is the smallest of the three, containing 25 companies. These are characterized by their rather high approval of both the incentives $(M=3.2, \mathrm{SD}=1.2)$ and the constraints $(M=4.2, \mathrm{SD}=$ 1.8) items. Their primary concern is the general lack of resources necessary for implementing EE programs. The average EE performance of utilities in the ambivalent cluster is higher than that of the passive cluster, but also significantly smaller than that of the active cluster (see Fig. 3). Compared to the cluster of active utilities, the ambivalent cluster has a slightly lower share of incorporated companies (48\%), which roughly corresponds to the overall sample average.

\section{Differences between the clusters}

An ANOVA was applied to check for significant differences between the clusters with regard to their EE performance, number of employees, number of large clients, and share of production. Because Levene's test of homogeneity of variances was significant $(p<0.001)$ for all these variables except the first, a Games-Howell post hoc test was performed for all of them, which is both adequate for dealing with heterogeneous variances and robust for clusters of different sizes (Field 2009).

Table 5 shows the results of the ANOVA. We found a significant main effect for "cluster" for all variables. The post-hoc test revealed a number of significant differences among the clusters. An outstanding pattern showed that the cluster of active utilities differs significantly from the other two clusters with regard to EE performance and number of employees, having the highest mean in both of them. Furthermore, with regards to the number of large clients it significantly differs from the ambivalent ones and with regards to the share of production it differs significantly from the passive ones. Utilities from the passive and ambivalent clusters are less distinct, displaying no significant differences in any of the four variables.

Factors influencing the energy efficiency performance and their interaction

The significant main effect for "cluster" indicates differences between clusters regarding EE performance. Using an ANCOVA, we have examined the effect of cluster membership on EE performance. In doing so, we have controlled for the number of employees, number of large clients, and share of production (co-variates). As in the 
Table 5 Results of the ANOVA, comparing the three clusters

\begin{tabular}{|c|c|c|c|c|c|c|c|c|}
\hline & \multirow[t]{2}{*}{$F$} & \multirow[t]{2}{*}{$p$} & \multicolumn{2}{|c|}{ Active $(n=35)$} & \multicolumn{2}{|c|}{ Passive $(n=41)$} & \multicolumn{2}{|c|}{ Ambivalent $(n=25)$} \\
\hline & & & $M$ & SD & $M$ & SD & $M$ & SD \\
\hline EE performance $\left[P_{\mathrm{EE}}\right]$ & 15.98 & 0.000 & $49.1^{\mathrm{a}, \mathrm{b}}$ & 18.7 & $26.2^{\mathrm{c}}$ & 15.3 & $34.3^{\mathrm{d}}$ & 19.7 \\
\hline Number of large clients & 4.25 & 0.017 & $107.6^{\mathrm{b}}$ & 140.6 & 55.0 & 76.8 & $39.8^{\mathrm{d}}$ & 37.2 \\
\hline Share of production [\%] & 4.67 & 0.012 & $27.5^{\mathrm{e}}$ & 36.1 & $6.4^{\mathrm{f}}$ & 17.5 & 18.6 & 37.1 \\
\hline Number of employees & 10.14 & 0.000 & $116.6^{\mathrm{a}, \mathrm{b}}$ & 168.4 & $17.7^{\mathrm{c}}$ & 21.5 & $29.3^{\mathrm{d}}$ & 24.7 \\
\hline
\end{tabular}

Results of post hoc-tests: ${ }^{\mathrm{a}}$ Significantly different from passive $(p<0.001) ;{ }^{\mathrm{b}}$ Significantly different from ambivalent $(p<0.05)$; ${ }^{\mathrm{c}}$ Significantly different from active $(p<0.001)$; ${ }^{\mathrm{d}}$ Significantly different from active $(p<0.05)$; ${ }^{\mathrm{e}}$ Significantly different from passive $(p<0.01)$; ${ }^{\mathrm{f}}$ Significantly different from active $(p<0.01)$

regression analysis, also legal form displayed a significant effect we have included it as a further factor in the analysis.

Table 6 displays the main results of the ANCOVA. Overall, the model explains about one third of the variance in EE performance. Neither of the covariates nor legal form revealed a significant main effect. This indicates that all these variables are not significantly related to EE performance when controlling for cluster membership and legal form. With respect to the clusters we found a significant main effect, $F(2,92)=10.63$, $p<0.001$. This main effect was qualified by an interaction effect among cluster membership and legal form, $F$ $(2,92)=3.81, p<0.05$, i.e., the effect of legal form on $\mathrm{EE}$ varied with cluster membership (see Fig. 3). It indicates that for utilities that are part of an administration cluster membership has a more pronounced effect on their EE

Table 6 Results of the ANCOVA with respect to utilities' EE performance

\begin{tabular}{llll}
\hline Variables & $d f$ & $F$ & $\eta$ \\
\hline Number of employees (co-variate) & 1 & 1.09 & 0.12 \\
Number of large clients (co-variate) & 1 & 0.02 & 0.00 \\
Share of production (co-variate) & 1 & 1.61 & 0.13 \\
Legal form & 1 & 0.43 & 0.07 \\
Cluster membership & 2 & $10.36^{* * *}$ & 0.43 \\
Legal form x Cluster membership & 2 & $3.81^{*}$ & 0.28 \\
Error & 92 & $(296.89)$ & 0.11 \\
\hline
\end{tabular}

The value enclosed in parentheses represents the mean square error

$R^{2}=0.33$

$* p<0.05 ; * * * p<0.001$ performance than for utilities with other legal forms (e.g., incorporated companies). Performing particularly well are utilities of the active cluster that are part of an administration.

\section{Discussion}

Discussion of the findings

In this study, we have identified three clusters of Swiss utilities based on their perspectives of the incentives and constraints for implementing EE programs. The subsequent ANOVA revealed a link between these perspectives and average EE performance, size, share of production, and number of large customers. The fact that the more active companies are, on average, larger also corresponds to the results of other general studies of companies, which found that small and medium enterprises pursue reactive environmental strategies mainly because of a lack of resources (Bianchi and Noci 1998; Aragón-Correa et al. 2008). This finding is also reflected in the different ratings of the incentives and constraints by the utilities in the three clusters.

Regarding the incentives, we would like to focus on two issues. First, the two most important incentives overall were improving the company's image and improving access to customers, whereas the prospect of starting a new business line and acquiring new customers seemed relatively unimportant. However, the relevance of these items varied by cluster. While the passive companies rated the former two items markedly lower, the latter two were quite relevant for the active companies. These results are plausible in the light of the ongoing changes in the Swiss electricity market. While 
the future liberalization offers new business opportunities to larger utilities with more organizational slack, there might be a considerable share of utilities that until now have not had the resources or have not been pushed by external factors to seriously consider promoting EE. This is in line with the results of the survey conducted by Eurelectric (2011), which found that one third of the polled electricity distribution companies had not determined whether promoting EE was a business opportunity or an unnecessary burden. The second issue is that reducing the negative consequences of the growing energy demands, such as increasing dependency from suppliers and higher capital expenditure requirements for production capacities or grid upgrades, did not seem to trigger the Swiss utilities to promote the EE of their customers. Moreover, no significant differences between the clusters were observed regarding that question. The reason why this issue is apparently less relevant for Swiss utilities than for those in other countries such as in the United States (see, for example, Hopper et al. 2009), could be the currently excellent condition of the Swiss electricity grid, so that even in times of high demand problems with outages are minor (Swissgrid 2012).

As to the constraints, we would also like to focus on two issues. The most relevant constraint was the widespread perception that there is a lack of human resources, resulting in a lack of time and knowledge. This was especially important for the companies in the ambivalent cluster. These companies usually lack the organizational slack to make the necessary adaptations required by the ongoing changes in the electricity market. This finding is in line with the aforementioned study of Laager et al. (2009), who found that a major constraint for Swiss utilities, especially small ones, to engage in EE programs is the lack of financial and human resources. The other issue is that the active and ambivalent utilities (that is, those who already offer more EE services) called for different legal frameworks and means to track the success of the EE programs, which would reward those utilities that are already promoting EE, be it financially or through a better public image.

The results of the ANCOVA suggest that cluster membership significantly influences utilities' EE performance. This effect depends, in particular, on the company's legal form. Utilities belonging to either the passive group or the ambivalent group had a higher chance of being more active in promoting EE if they were incorporated companies. Meanwhile, the opposite effect could be observed for the active utilities. One explanation for this pattern may be that incorporated companies, even small ones, are forced to assess their market position regularly, whereas those that are part of an administration have a more or less given mission. This means that incorporated companies can generally be faster in adopting EE measures that promise clear financial gains and an improvement of the companies' public image (i.e., picking the "low hanging fruits"). But at the same time, when it comes to offering EE services that promise no or only marginal returns, both from a financial and an image perspective, political pressure might be needed to implement them. But this might only be possible for larger communities, which usually host larger utilities with an aboveaverage size, because only these communities have both adequate financial resources and direct control of the utilities.

\section{Critical reflections}

Before we conclude, we would like to reflect critically on three points. The first is the selection and measurement of the 20 incentives and constraints items. These have not only been taken from international sources, but also strongly focus on the Swiss context. This reduces the generalizability of the results and the possibility of linking them to existing scientific literature on barriers and drivers, which is especially unfortunate with regard to barriers. A large body of literature already exists on this topic, which structures them according to theoretical frameworks (e.g., Weber 1997; Sorrell et al. 2000) and explicitly addresses the so-called efficiency gap; i.e., why more energy is consumed than would be economically optimal (Jaffe and Stavins 1994). Furthermore, all items were measured using a binary scale, which makes the utilities' profiles, with respect to the incentives and constraints, less distinct than if rating scales were used. However, considering that the objective of our study was specifically to analyze the Swiss situation and that our analysis yielded clear and plausible results, this compromise in data collection seems justified.

The second point concerns the quantification of the 20 incentive and constraint items. Because a broad spectrum of opinions might have been present in the companies surveyed, the assessment of the items might be partially dependent on the personal opinions of the 
respondents. This is not a big concern with regard to the many small utilities in the survey, which often have less than ten employees. In these cases, the company's CEO usually filled out the survey, which provided a good representation of the company's perspective. In the case of larger companies, this might have been more of an issue, as one cannot assume that the surveys were filled out by a manager or member of the board. To lessen the resulting variance, in the accompanying letter, we asked that the survey be forwarded to the person responsible for EE, whose responses could be assumed to represent the company's views on EE.

The third point is the choice of the dependent variable. Using a binary assessment of companies' different activities does not allow for acknowledging the stringency with which they are implemented or, in other words, the efforts put into them. This might cause a bias favoring large utilities who can afford to implement a broader range of measures. And while for specific EE programs the energy savings can be determined quite adequately and efficiently by using simple engineering estimations (Cabrera et al. 2012), there is no single best way to measure utilities' performance with regard to $\mathrm{EE}$ in a standardized (and hence comparable) way. As Horowitz (2011, p. 43) puts it, the challenge lies in measuring "the volume of fuel and energy that would have been demanded but was not." Demand projections (for example, as used in Hopper et al. 2009) are also uncertain, as reduction targets may be set too ambitiously and the utilities may eventually fail to meet them (Kaufman and Palmer 2012). Furthermore, an EE performance assessment based on energy consumption data raises a number of questions, such as how long the time series should be and to which baseline it should be compared. Therefore, our approach of using an expert-weighted sum of activities seems the most transparent, particularly considering the amount and accuracy of data that would be required for a more complex approach.

Origin to each of these three points of concern was primarily the tradeoff between the surveys' length and its response rate. Because we emphasized the latter, our survey was kept as short as possible and was limited to categorical items. Or motivation for doing so was that for the past years, Swiss utilities have had to cope with a large number of surveys and inquiries by various governmental agencies, industrial bodies, and research institutions, which has been prompted by the recent liberalization of the electricity market for large consumers and the planned opening for all customers in 2015. The rather high response rate suggests that our strategy of using a short questionnaire was effective.

\section{Conclusions}

The results of our analysis of Swiss utilities confirm the findings of previous studies, such as those by Hopper et al. (2009) and Carley (2012). There is indeed a link between utilities' characteristics and their promotion of EE. This seems to hold true even in the absence of a national policy framework that aims at decoupling utilities' revenues from their sales of electricity. However, due to the large heterogeneity of Swiss utilities, the links found were neither linear nor monocausal. Therefore, the activity of a utility in promoting EE should be seen as the result of an interplay among different variables. For example, we found that company size alone was not a robust predictor of the utilities' EE performance. While a certain size might be a necessary condition for being an active promoter of EE, it is not sufficient to explain the variance in the utilities' behavior, which is possibly also influenced by other factors, such as the companies' perceived incentives and constraints or, as our cluster analysis suggests, by whether they have an active, passive, or ambivalent perspective regarding the promotion of EE.

Thus, we recommend that future studies examine this issue in more detail. A better understanding of the influence of the utilities' organizational structure and ownership on their EE strategy would be of special interests since our results suggest that the effect of legal form may vary between different types of utilities. Furthermore, to better understand the influence of the different sociotechnical contexts, qualitative comparisons between the situations in different countries or regions as well as quantitative international studies that compare utilities on the basis of a standardized set of parameters are both necessary.

We conclude with a recommendation for policymakers that aim at designating electricity utilities as agents for promoting EE: If the differences between the utilities' characteristics and their experience with EE programs are as huge as they are in Switzerland, there certainly is no single best policy. Rather, one should consider that policies differentially affect distinct groups of utilities, depending on their available 
resources and their different perspectives regarding incentives and constraints for promoting EE. Utilities that are already quite active in offering EE services will require further incentives that encourage them to pursue their current course. One option would be the introduction of standardized measures and labels for quantifying energy savings through efficiency programs, which they could use for marketing purposes. Another potentially attractive policy measure for these companies would be the introduction of a national incentive framework, such as the system of saving obligations coupled with white certificates, which is foreseen by the new Swiss energy strategy. However, such an instrument would need to be designed in a way that previous efforts are acknowledged for. If this is not done, active utilities will be disadvantaged compared to those who can still pick some low hanging fruits. Meanwhile, the group of ambivalent companies that are mainly constrained by their lack of staff, time, and knowledge may profit less from such schemes, as they will face difficulties in complying with them. While mergers between such companies might free some of these scarce resources, it will nonetheless be hard to achieve. Many of the utilities are owned by communities, which would most likely oppose such consolidation efforts. For them it would mean to give up some of the power they have held in the past. Hence, establishing regional intelligence or competence centers might help ambivalent utilities to overcome their lack of resources. These centers could provide the regions' utilities with knowledge and practical support for designing and implementing standardized and effective EE programs. Additionally, the many passive utilities, which sometimes employ no more than a handful of people, will find it difficult to establish the role of a change agent in promoting EE primarily due to their limited resources. If utilities are to play a prominent role in the implementation of the new national energy strategy, consolidation seems inevitable. This may be supported by the upcoming liberalization of the Swiss electricity retail market for all consumers, as this will raise the administrative standards for utilities. Small companies will have a very hard time keeping up with these.

Acknowledgements This study is based on a project under the umbrella of ETH Seed Sustainability (http://www.seed.ethz.ch). We thank all the experts involved in the study, particularly Roger Sonderegger for his help with the design of the survey. We extend our thanks to Roman Seidl, Timo von Wirth, Jörn Hoppmann,
Bastian Girod, and Nina Boogen for their valuable comments and feedback on previous versions of the manuscript and Christine Gmür for proofreading the final manuscript. The authors would also like to acknowledge the very detailed and helpful feedback offered by five anonymous reviewers.

\section{References}

Aragón-Correa, J. A., Hurtado-Torres, N., Sharma, S., \& GarcíaMorales, V. J. (2008). Environmental strategy and performance in small firms: a resource-based perspective. Journal of Environmental Management, 86(1), 88-103.

Bertoldi, P., \& Rezessy, S. (2009). Energy saving obligations and tradable white certificates. Report prepared by the Joint Research Centre of the European Commission. Brussels: European Commission.

Bertoldi, P., Rezessy, S., Lees, E., Baudry, P., Jeandel, A., \& Labanca, N. (2010). Energy supplier obligations and white certificate schemes: comparative analysis of experiences in the European Union. Energy Policy, 38(3), 1455-1469.

BFE. (2012). Schweizerische Elektrizitätsstatistik 2011 [Swiss Electricity Statistics 2011]. Bern: Bundesamt für Energie.

Bianchi, R., \& Noci, G. (1998). "Greening" SMEs' competitiveness. Small Business Economics, 11(3), 269-281.

Cabrera, D., Seal, T., Bertholet, J.-L., Lachal, B., \& Jeanneret, C. (2012). Evaluation of energy efficiency program in Geneva. Energy Efficiency, 5(1), 87-96.

Carley, S. (2012). Energy demand-side management: new perspectives for a new era. Journal of Policy Analysis and Management, 31(1), 6-32.

Cometta, C., Hannich, F., \& Rauh, M. (2010). Smart Metering: (K)ein Thema für Schweizer Energieversorger [Smart metering-_not) a focus of Swiss energy suppliers]? Bulletin VSE/electrosuisse, 12, 1-4.

Cooremans, C. (2011). Make it strategic! Financial investment logic is not enough. Energy Efficiency, 4(4), 473-492.

Crossley, D. J. (2008). Tradeable energy efficiency certificates in Australia. Energy Efficiency, 1(4), 267-281.

Eurelectric. (2011, September 16, 2013). The promotion of energy efficiency services - a survey among electricity companies. http://www.eurelectric.org/media/26220/energy_efficiency_ survey_lr-2011-030-0376-01-e.pdf

Field, A. (2009). Discovering statistics using SPSS. London: SAGE Publications Ltd.

Fthenakis, V., \& Kim, H. C. (2009). Land use and electricity generation: a life-cycle analysis. Renewable and Sustainable Energy Reviews, 13(6-7), 1465-1474.

Giraudet, L. G., Bodineau, L., \& Finon, D. (2012). The costs and benefits of white certificates schemes. Energy Efficiency, 5(2), 179-199.

Hopper, N., Barbose, G., Goldman, C., \& Schlegel, J. (2009). Energy efficiency as a preferred resource: evidence from utility resource plans in the Western US and Canada. Energy Efficiency, 2(1), 1-16.

Horowitz, M. (2011). Measuring the savings from energy efficiency policies: a step beyond program evaluation. Energy Efficiency, 4(1), 43-56. 
Jaffe, A. B., \& Stavins, R. N. (1994). The energy-efficiency gap. What does it mean? Energy Policy, 22(10), 804-810.

Kaufman, N., \& Palmer, K. (2012). Energy efficiency program evaluations: opportunities for learning and inputs to incentive mechanisms. Energy Efficiency, 5(2), 243-268.

Laager, D., Bettler, M., Carle, G., Meier, M., Miguel, S., Wiederkehr, K., \& Wittwer, R. (2009). Befragung zur Bedeutung von Energieeffizienz in der Strombranche [Survey on the relevance of energy efficiency in the energy sector]. Aarau: Verband Schweizer Elektrizitätsunternehmen.

Mundaca, L. (2008). Markets for energy efficiency: exploring the implications of an EU-wide 'Tradable White Certificate' scheme. Energy Economics, 30(6), 3016-3043.

Nabe, C., Beyer, C., Brodersen, N., Schäffler, H., Adam, D., Heinemann, C., et al. (2009). Einführung von lastvariablen und zeitvariablen Tarifen [Introduction of variable tariffs with respect to load and time]. Bonn: Deutsche Bundesnetzagentur für Elektrizität, Gas, Telekommunikation, Post und Eisenbahnen.

Pavan, M. (2012). Tradable white certificates: experiences and perspectives. Energy Efficiency, 5(1), 83-85.

Pyrko, J., \& Darby, S. (2011). Conditions of energy efficient behaviour - a comparative study between Sweden and the UK. Energy Efficiency, 4(3), 393-408.

Sonderegger, R. W. (2005). Minimale wirtschaftliche Grösse von EVU-Wie gross muss ein kommunales EVU sein, um wirtschaftlich überleben zu können [Minimal size of municipal utilities - how large must they be in order to survive]? Bulletin VSE/electrosuisse, 20(2005), 1-2.

Sonderegger, R. W., \& Schedler, K. (2010). Betriebliche Steuerung von kommunalen ElektrizitätsversorgungsunternehmenSchlussbericht zur Follow-up Studie 2009 [Operational management of Swiss utilities - final report of the follow-up study 2009]. St. Gallen: Universität St. Gallen.

Sorrell, S., Schleich, J., Scott, S., O’Malley, E., Trace, F., Boede, E., et al. (2000). Reducing barriers to energy efficiency in public and private organizations. Brighton: SPRU, Univ. of Sussex.

SPSS Inc. (2001). The SPSS two-step cluster component: a scalable component to segment your customers more effectively. White Paper, Technical Report. Chicago: SPSS.
Suerkemper, F., Thomas, S., Osso, D., \& Baudry, P. (2012). Costeffectiveness of energy efficiency programmes - evaluating the impacts of a regional programme in France. Energy Efficiency, 5(1), 121-135.

Sullivan, D., Wang, D., \& Bennett, D. (2011). Essential to energy efficiency, but easy to explain: frequently asked questions about decoupling. The Electricity Journal, 24(8), 56-70.

Swissgrid. (2012). Jahresbericht 2011 [2011 Annual Report]. Frick: Swissgrid.

Swiss Federal Council. (2013). Botschaft zum ersten Massnahmenpaket der Energiestrategie 2050 und zur Atomausstiegsinitiative [Message to the parliament on the first package of measures for implementing the Energy Strategy 2050 and to the initiative for phasing out nuclear power]. Bern: Swiss Federal Council.

Tan, J., \& Peng, M. W. (2003). Organizational slack and firm performance during economic transitions: two studies from an emerging economy. Strategic Management Journal, 24(13), 1249-1263.

Tian, Z., Ramakrishnan, R., \& Livny, M. (1997). BIRCH: a new data clustering algorithm and its applications. Data Mining and Knowledge Discovery, 1(2), 141-182182.

Ürge-Vorsatz, D., \& Metz, B. (2009). Energy efficiency revisited: how far does it get us in controlling climate change? Energy Efficiency, 2(4), 287-292.

Vine, E., Hall, N., Keating, K., Kushler, M., \& Prahl, R. (2012). Emerging issues in the evaluation of energy-efficiency programs: the US experience. Energy Efficiency, 5(1), 5-17.

Vojdani, A. (2008). Smart integration. Power and Energy Magazine, IEEE, 6(6), 71-79.

Waide, P., \& Buchner, B. (2008). Utility energy efficiency schemes: savings obligations and trading. Energy Efficiency, 1(4), 297-311.

Weber, L. (1997). Some reflections on barriers to the efficient use of energy. Energy Policy, 25(10), 833-835.

Yergin, D. (2006). Ensuring energy security. Foreign Affairs, $85(2), 69-82$.

Zarnikau, J. (2012). The many factors that affect the success of regulatory mechanisms designed to foster investments in energy efficiency. Energy Efficiency, 5(3), 393-410. 